\title{
Feasibility of combining two individualized lung recruitment maneuvers at birth for very low gestational age infants: a retrospective cohort study
}

\author{
Zalfa Kanaan ${ }^{1}$, Coralie Bloch-Queyrat ${ }^{2}$, Marouane Boubaya², Vincent Lévy², Pascal Bolot ${ }^{1}$ and Paul Waszak ${ }^{1 *}$
}

\begin{abstract}
Background: Lung recruitment at birth has been advocated as an effective method of improving the respiratory transition at birth. Sustained inflations (SI) and dynamic positive end-expiratory pressure (PEEP) were assessed in clinical and animal studies to define the optimal level. Our working hypothesis was that very low gestational age infants $($ VLGAl) $<32$ weeks' gestation require an individualized lung recruitment based on combining both manoeuvers.

Methods: Between 2014 and 2016, 91 and 72 inborn VLGAl, requiring a respiratory support beyond a continuous positive airway pressure (CPAP) $=5 \mathrm{cmH} 2 \mathrm{O}$, were enrolled before and after introducing these manoeuvers based on progressive increase in SI up to $15 \mathrm{~s}$, with simultaneous gradual increase in PEEP up to $15 \mathrm{cmH} 2 \mathrm{O}$, according to the cardiorespiratory response. Retrospective comparisons of the incidence of mechanical ventilation $(\mathrm{MV})<72 \mathrm{~h}$ of life, short-term and before discharge morbidity were then performed.

Results: Among extremely low gestational age infants (ELGAI) < 29 weeks' gestation, the following outcomes decreased significantly: intubation (90 to 55\%) and surfactant administration (54 to 12\%) in the delivery room, MV (92 to $71 \%$ ) and its mean duration $<72 \mathrm{~h}$ of life ( $45 \mathrm{~h}$ to $13 \mathrm{~h}$ ), administration of a 2 nd dose of surfactant ( 35 to $12 \%$ ) and postnatal corticosteroids (52 to 19\%), and the rate of bronchopulmonary dysplasia (23 to 5\%). Among VLGAl, all of these results were also significant. Neonatal mortality and morbidity were not different.

Conclusions: In our setting, combining two individualized lung recruitment maneuvers at birth was feasible and may be beneficial on short-term and before discharge pulmonary outcomes. A randomized controlled trial is needed to confirm these results.
\end{abstract}

Keywords: Neonatal resuscitation, Lung recruitment, Dynamic PEEP, Sustained inflation, Bronchopulmonary dysplasia

\section{Background}

Resuscitating premature infants at birth aims to stimulate spontaneous breathing and establish an optimal functional residual capacity without harming the lungs [1]. To this end, lung recruitment maneuvers have been

\footnotetext{
* Correspondence: paul.waszak@ch-stdenis.fr

'Service de Réanimation Néonatale et Néonatalogie, Hôpital Delafontaine, 2 rue Dr Delafontaine, 93205 Saint-Denis, France

Full list of author information is available at the end of the article
}

under investigation over the past two decades [2-6]. To date, despite numerous studies, no clear definition of the optimal inflation duration, nor of positive end-expiratory pressure (PEEP) optimal level exists. According to current knowledge on the respiratory transition at birth [7], sustained inflation (SI) aerates the fluid-filled lungs homogeneously during the initial fetal-neonatal transition phase, and thereafter, adequate PEEP helps to maintain the fluid in the interstitial tissue. 
Current international guidelines recommend starting resuscitation of premature infants with intermittent positive pressure ventilation, using a PEEP of $5 \mathrm{cmH} 2 \mathrm{O}$ with the first insufflations of 2-3 s (but not greater than $5 \mathrm{~s})[8,9]$. However, these measures are probably not sufficient for recruiting the optimal functional residual capacity.

Lung recruitment (LR) at birth using SI of 15-20 s was assessed in numerous randomized controlled trials (RCTs) summarized in 2 recent meta-analyses [10, 11]. Despite encouraging results such as a reduced need for intubation, no benefit was found for reduction of mortality or bronchopulmonary dysplasia (BPD). However, studies in the premature lamb have shown better oxygenation, lung mechanics, and end-expiratory global lung volume after a dynamic PEEP strategy based on a step-by-step PEEP increase far beyond $5 \mathrm{cmH} 2 \mathrm{O}$ compared with a nonoptimized SI strategy $[4,6]$. However, none of these differences were observed when the dynamic PEEP strategy was compared with a SI strategy optimized by real time electrical impedance tomography for the duration of the inflation [5]. We hypothesized that individualized LR maneuvers combining dynamic PEEP and gradually extended SI, as needed, would lower the incidence of mechanical ventilation (MV) in the first $72 \mathrm{~h}$, without increasing neonatal complications. To this end, we retrospectively compared short-term and before discharge outcomes, before and after introducing LR maneuvers in very low gestational age infants (VLGAI) < 32 weeks of gestation and especially in the subgroup of extremely low gestational age infants $($ ELGAI) $<29$ weeks of gestation, with higher morbidity and mortality rates.

\section{Methods}

\section{Population}

Our tertiary level hospital covers the Saint-Denis area in the north of Paris, France, with a rate of $\sim 4500$ deliveries/year. Inborn VLGAI requiring pulmonary resuscitation born from July 2014 to June $2015(n=91)$ and for all of $2016(n=72)$ were included in this retrospective cohort study. A 6-month gap between both periods was needed to introduce LR maneuvers to the NICU team. Data were collected from patients' medical records and reports.

A total of 242 VLGAI were managed during these periods (119 during 2014/2015 and 123 during 2016). We excluded infants transferred from other hospitals $(n=12)$ and $(n=14)$, infants suffering from major congenital anomalies $(n=3)$ and $(n=3)$, and newborns requiring no respiratory support beyond a CPAP value of $5 \mathrm{cmH} 2 \mathrm{O}(n=13)$ and $(n=10)$ in $2014 / 2015$ and 2016, respectively. Respiratory support was started based on currently used international guidelines $[8,9]$. The adherence to the new protocol was judged on the written words describing the resuscitation in the DR. During the second period, 24/96 (25\%) pulmonary resuscitations did not follow the LR algorithm and were excluded from the analysis.

Data collection was approved by the local area ethics committee on human research (Comité Local d'Ethique d'Avicenne belonging to Groupe Hospitalier Paris-SeineSaint-Denis) which allowed a waiver of informed consent for this retrospective study (Protocol No. CLEA2017-031).

\section{Intervention (Fig. 1)}

The intervention was the introduction of the LR strategy. In the 2014/2015 period, the respiratory assistance of VLGAI was conducted according to international recommendations (PEEP of $5 \mathrm{~cm} \mathrm{H} 2 \mathrm{O}$, inflation duration of $2-3 \mathrm{~s}$, peak inspiratory pressure of $20-25 \mathrm{cmH} 2 \mathrm{O}$ ) using a face mask with a T-piece resuscitator (Neopuff, Fisher \& Paykel, Auckland, New-Zealand), followed by intubation if the baby remained apneic or cyanotic with a pulse oxygen saturation $(\mathrm{SpO} 2)<75 \%$ at $5 \mathrm{~min}$ of life whatever the fraction of inspired oxygen (FiO2), or with a heart rate $(\mathrm{HR})<100 / \mathrm{min}$ or an $\mathrm{FiO} 2>0.4$ at $10 \mathrm{~min}$ of life in order to achieve an $\mathrm{SpO} 2>85 \%$. During 2016, respiratory support was changed to gradual increase in inflations duration (from 3 to 5 , to 10 , then $15 \mathrm{~s}$ ), as needed, and performed with a simultaneous increase in PEEP every 1 to 2 SI from 5 to $8,10,12$, then 15 $\mathrm{cmH} 2 \mathrm{O}$, according to the clinical response, which included persistent bradycardia, apnea or gasping. A gradual decrease in PEEP was performed when $\mathrm{FiO} 2$ reached 0.4 , while SIs were stopped when regular spontaneous breathing was observed. In case of severe asphyxia, emergency intubation with or without chest compressions did not cancel the LR strategy. During both periods, the resuscitation team included at least a neonatologist, a pediatric resident, and a midwife. The team member at the head of each newborn kept track of the titrating of SIs by counting aloud each duration, and announcing the PEEP level set at the PEEP cap located on the T-piece. The PIP level which was not modified with the PEEP level, was eventually increased by turning the ad-hoc knob by the team member closest to it.

\section{Monitoring in the DR}

Postnatal hypothermia was prevented by using radiant heaters and warmed blankets. After drying, extremely low gestational age infants (ELGAIs) $<29$ weeks were immediately wrapped in a sterile, transparent plastic bag. The head was covered by a warmed cap. Temperature was monitored via a cutaneous sensor. $\mathrm{HR}$ was measured by stethoscope and then monitored by an $\mathrm{SpO} 2$ sensor $\left(\right.$ Massimo $^{\mathrm{TM}}$ ) placed at the right hand. 


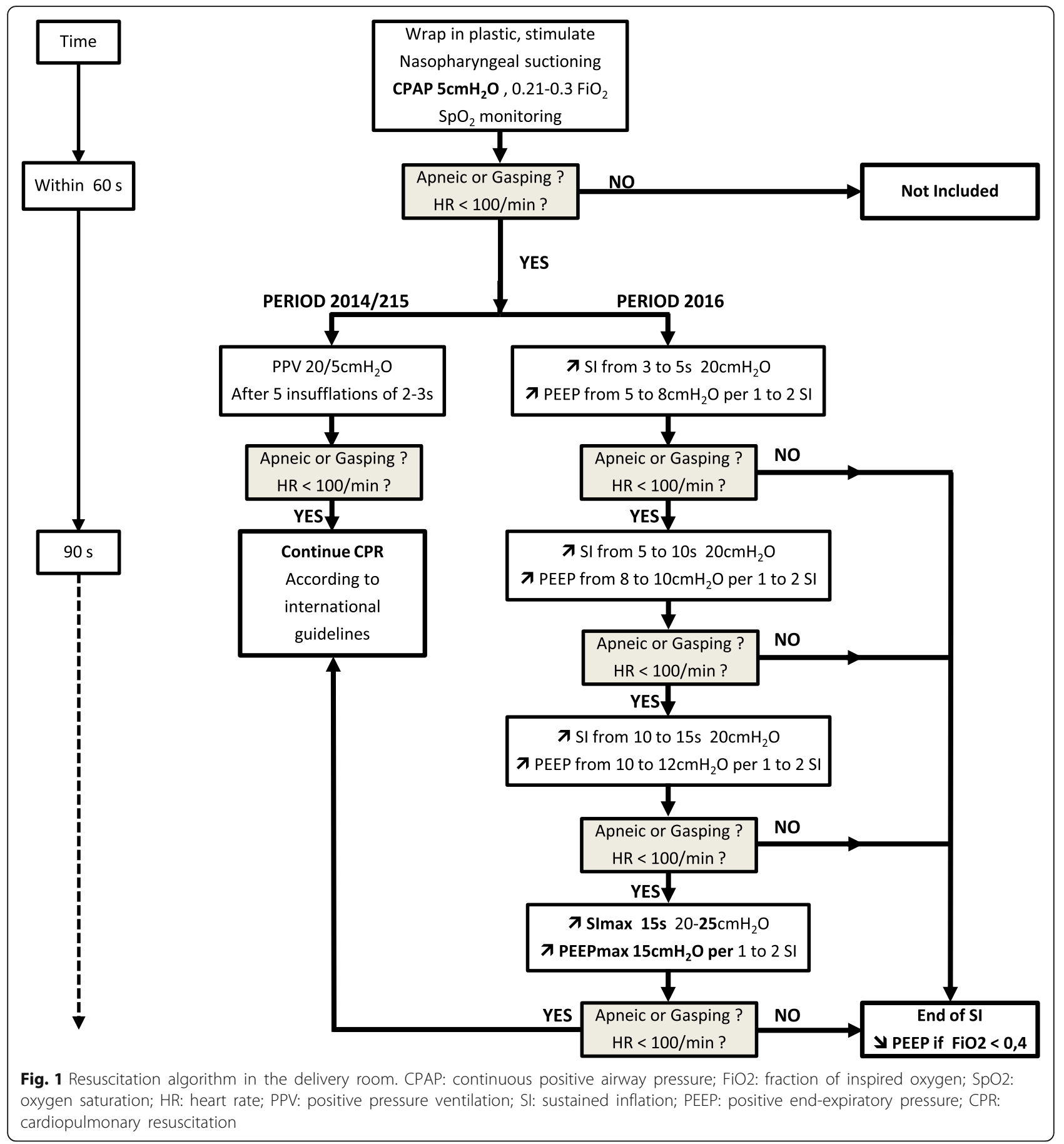

Transport to the neonatal intensive care unit (NICU)

A preheated neonatal transport incubator was used for the transfer to the NICU. During both periods, infants were ventilated (invasively or not) using a Babylog 8000 (Dräger, Lübeck, Germany). Continuous positive airway pressure (CPAP) or noninvasive ventilation (NIV) was provided during the transfer by using nasal cannula (Neotech RAM Cannula $^{\mathrm{Tm}}$, Valencia, CA, USA).

\section{Co-interventions}

\section{Obstetric management}

Some changes in obstetric treatment were introduced in October 2016: antibiotic therapy duration after preterm premature rupture of membrane was shortened from 5 to 3 days [12]; and magnesium sulfate was infused to pregnant women prior to the preterm birth of infants < 33 weeks' gestation [13]. 


\section{NICU management}

Neonatal management was as follows:

- Intubation criteria did not change: (i) in the DR, they remained as stated above; (ii) in the NICU, the criteria were an FiO2 $>0.4$, frequent ( $>6$ occurrences during $6 \mathrm{~h}$ ) or severe apneas ( $>1$ per $6 \mathrm{~h}$ requiring bag-mask ventilation).

- CPAP or NIV was maintained using the InfantFlow ${ }^{\odot}$ biphasic nCPAP device (SEBAC, Gennevilliers, France). The synchronized mode was used in case of hypercapnia or moderate apnea despite caffeine treatment.

- During 2016, permissive hypercapnia was introduced with a maximal tolerated pCO2 limit of $65 \mathrm{mmHg}$ (vs $55 \mathrm{mmHg}$ during 2014/2015).

- Oxygen level was adjusted to obtain an SpO2 target range of 87-93\% during 2016 instead of $85-95 \%$ during 2014/2015.

- During 2016, the maintenance dose of caffeine ( $5 \mathrm{mg} / \mathrm{kg} /$ day) was doubled in case of moderate apnea.

- During the second period, the first surfactant administration $(200 \mathrm{mg} / \mathrm{kg}$ of Curosurf, Chiesi, Parma, Italy) was indicated when FiO2 exceeded 0.25 and 0.30 in ELGAIs and VLGAIs respectively, instead of 0.4 during the first period, whatever the gestational age (GA). During both periods, a second dose $(100 \mathrm{mg} / \mathrm{kg})$ was administered when $\mathrm{FiO} 2$ exceeded 0.4. If the infant was not intubated, the intubation-surfactant-extubation (INSURE) procedure was performed, and considered successful (without MV) if the extubation was carried out less than 1 hour later.

- Postnatal corticosteroid therapy criteria remained the same for premature infants more than 21 days old: persistent need for MV with $\mathrm{FiO} 2$ exceeding 0.4 , or after failure of extubation.

- During 2016, early-rescue high frequency oscillation (HFO) ventilation was introduced in case of INSURE failure or an early ( $<72 \mathrm{~h}$ of life) need for invasive PPV, while volume guarantee ventilation was introduced to accelerate the weaning process. A change from a systematic sedation-analgesia toward an individualized approach based on the EDIN scale [14] was also performed in invasively ventilated infants.

- No major changes in the nutrition protocol occurred, except for probiotics (Lactobacillus casei and Lactobacillus rhamnosus) introduced in April 2016.

\section{Primary and secondary outcomes}

The primary outcome was the incidence of MV in the first $72 \mathrm{~h}$. Secondary outcomes were the rate of intubation in the DR; Apgar score at $5 \mathrm{~min}$; surfactant use; ventilator days; postnatal corticosteroids; mortality and morbidity including physiologic BPD [12]; pneumothorax; intraventricular hemorrhage $(\mathrm{IVH})>$ grade 2 [13]; periventricular leukomalacia [14]; treated patent ductus arteriosus (PDA); necrotizing enterocolitis $(\mathrm{NEC}) \geq$ stage $2 \mathrm{a}[15]$; and retinopathy of prematurity $(\mathrm{ROP})>$ stage 2 [16].

\section{Statistical analysis}

Data are summarized as median and interquartile range for quantitative data and as count and percentage for categorical data. Statistical analyses were performed using chi-squared test or Fisher's exact test for categorical variables and the $\mathrm{t}$-test or Mann-Whitney U-test for continuous variables. All outcomes with $p<0.10$ in univariate analysis were analyzed with multiple logistic regression. Adjustments were made for confounding, such as sex, birth weight, GA, mode of delivery and low Apgar score $(<5)$ at $1 \mathrm{~min}$. Similar analyses were performed for the infants of GA between 29 and 31 weeks and ELGAI subgroup. No adjustment of $P$ values was performed to account for multiple comparisons because subgroups analyses are considered exploratory. All tests were two-sided at a 0.05 significance level. Analyses were carried out using $\mathrm{R}$ statistical software version 3.3.2.

\section{Results}

Comparability of study groups (Table 1)

Although both periods were similar regarding all baseline population characteristics, the cesarean section rate increased from 58 to $74 \%$ without reaching significance $(p=0.06)$.

\section{Intervention}

As stated above, in 2016, 10 newborns requiring no respiratory support beyond a CPAP value of $5 \mathrm{cmH} 2 \mathrm{O}$ were excluded from the study, as were also excluded 24/ 96 (25\%) newborns who did not benefited from the LR algorithm. That is, without any written word on increased inflation time $>3 \mathrm{~s}$ or PEEP value $>5 \mathrm{cmH} 2 \mathrm{O}$ despite a low Apgar score. Data concerning the LR maneuvers in 2016 were available for 66/72 (92\%) patients: 20 (30\%) infants required inflations with a peak inspiratory pressure of $20 \mathrm{cmH} 2 \mathrm{O}$ but without any recruitment maneuvers beyond five 3-s-inflations, 13 (20\%) required an $\mathrm{SI}=5 \mathrm{~s}$ with a $\mathrm{PEEP}=8 \mathrm{cmH} 2 \mathrm{O}, 24(36 \%)$ required an $\mathrm{SI}=10 \mathrm{~s}$ with a PEEP $=10-12 \mathrm{cmH} 2 \mathrm{O}$, while only 9 $(14 \%)$ required an $\mathrm{SI}=15 \mathrm{~s}$ with a $\mathrm{PEEP}=15 \mathrm{cmH} 2 \mathrm{O}$. Without reaching significance $(p=0.58$ and $p=0.23$, respectively) the median maximal $S I$ and PEEP were higher in the ELGAI subgroup (10 s and $10 \mathrm{cmH} 2 \mathrm{O}$ ) than in the 29- to 31-week subgroup ( $5 \mathrm{~s}$ and $8 \mathrm{cmH} 2 \mathrm{O}$ ) (Table 2). 
Table 1 Very Low Gestational Age Infants < 32 weeks GA Population Characteristics

\begin{tabular}{|c|c|c|}
\hline & $\begin{array}{l}\text { Period } 1 \\
(2014 / 2015) \\
N=91\end{array}$ & $\begin{array}{l}\text { Period } 2 \\
(2016) \\
N=72\end{array}$ \\
\hline Female, n (\%) & $41(45)$ & $30(42)$ \\
\hline Gestational age, weeks (median) [1st Qu; 3rd Qu] & $28[27 ; 30]$ & $28[27 ; 30]$ \\
\hline Birth weight, g (median) [1st Qu; 3rd Qu] & $1030[850 ; 1356]$ & $1028[879 ; 1344]$ \\
\hline IUGR, n (\%) & $21(23)$ & $17(24)$ \\
\hline Cesarean Section, n (\%) & $53(58)$ & $53(74)$ \\
\hline \multicolumn{3}{|l|}{ Premature birth causes, n (\%) } \\
\hline - Chorioamnionitis & $28(31)$ & $14(19)$ \\
\hline - Pre-eclampsia + abnormal FHR & $38(42)$ & $41(57)$ \\
\hline - Other & $12(13)$ & $9(13)$ \\
\hline - Idiopathic & $13(14)$ & $8(11)$ \\
\hline \multicolumn{3}{|l|}{ Antenatal corticosteroids, n (\%): } \\
\hline - None & $15(17)$ & $8(11)$ \\
\hline - One dose & $21(23)$ & $12(17)$ \\
\hline - Two doses & $55(60)$ & $52(72)$ \\
\hline
\end{tabular}

GA Gestational age, IUGR Intrauterine growth restriction (<3rd percentile), FHR Fetal heart rate; No significant difference between period 1 and 2

\section{DR management data (Table 2)}

The rate of the Apgar score $<5$ at 5 min was divided by 8 in VLGAI and by 4 in ELGAI, while no Apgar score < 5 at 5 min was observed in the 29- to 31-week stratum, but without reaching significance. A similar fall in the rate of adrenaline administration in the DR was observed without reaching significance. The rate of chest compressions was also not significantly divided by 6 in VLGAI, while no more chest compressions were practiced in the 29- to 31-week subgroup. Moreover, the rate of intubation in the DR significantly decreased by $52 \%$ in VLGAI $(p<0.01)$, and specifically by $60 \%$ in the 29 - to 31 -week subgroup $(p<0.01)$, and by $39 \%$ in the ELGAI subgroup $(p<0.01)$. Exogenous surfactant administration in the DR decreased significantly by $59 \%$ in VLGAI $(p<$
0.01 ), and especially by $78 \%$ in the ELGAI subgroup ( $p<$ 0.01 ). The multivariate analysis did not change the results.

\section{MV and respiratory outcomes (Table 3)}

The primary outcome, MV in the first $72 \mathrm{~h}$, showed a statistically significant $28 \%$ decrease in VLGAI ( $p$ and adjusted $p<0.01$ ), with a $43 \%$ decrease in the 29 - to 31 week subgroup ( $\mathrm{p}$ and adjusted $p<0.05$ ), and a $23 \%$ decrease in the ELGAI subgroup $(p<0.05)$. Analyzing the primary outcome as a continuous variable showed a significant decrease in MV duration from 13 to $7 \mathrm{~h}$ (p and adjusted $p<0.05)$ and from 45 to $13 \mathrm{~h}(p<0.01)$ in VLGAI and ELGAI, respectively. Significantly more infants were ventilated by HFO in both subgroups but the

Table 2 Delivery Room Management Data

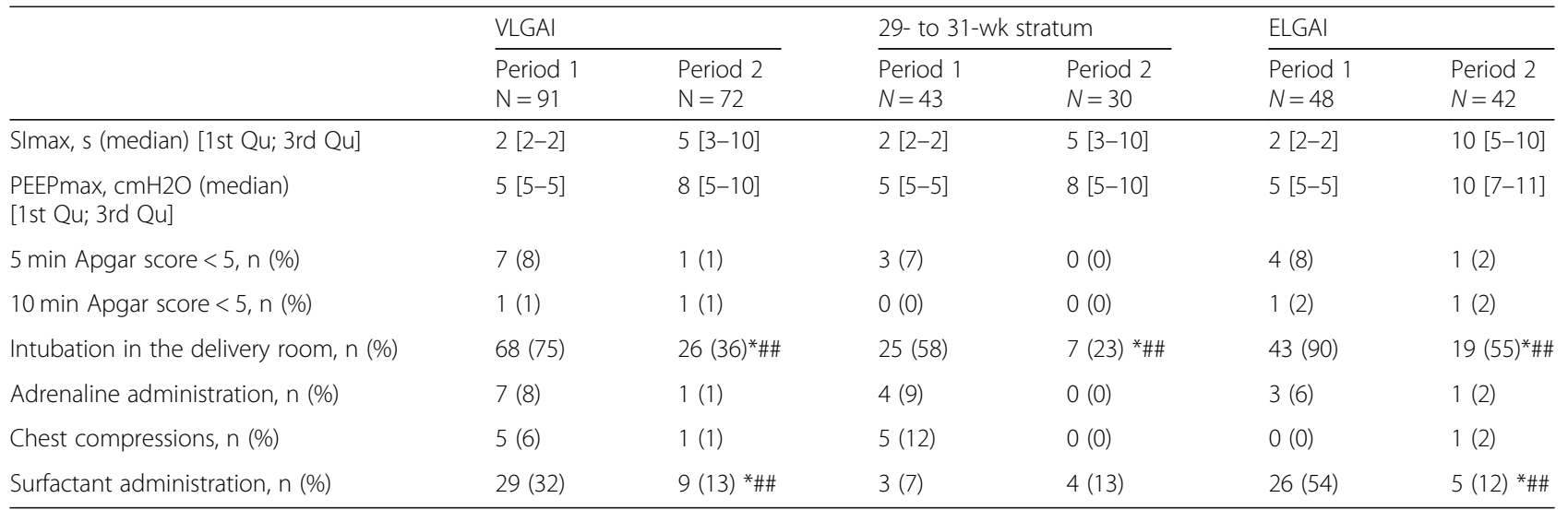

VLGAI: very low gestational age infants < 32 weeks; ELGAl: extremely low gestational age infants < 29 weeks; SImax: maximal sustained inflation; PEEPmax: maximal positive end-expiratory pressure; ${ }^{*} \#$ : $\mathrm{p}$ and adjusted $p<0.01$ 
Table 3 Mechanical Ventilation and Respiratory Outcomes

\begin{tabular}{|c|c|c|c|c|c|c|}
\hline & \multicolumn{2}{|l|}{ VLGAI } & \multicolumn{2}{|c|}{ 29- to 31-wk stratum } & \multicolumn{2}{|l|}{$\underline{E L G A I}$} \\
\hline & $\begin{array}{l}\text { Period } 1 \\
\mathrm{~N}=91\end{array}$ & $\begin{array}{l}\text { Period } 2 \\
\mathrm{~N}=72\end{array}$ & $\begin{array}{l}\text { Period } 1 \\
\mathrm{~N}=43\end{array}$ & $\begin{array}{l}\text { Period } 2 \\
\mathrm{~N}=30\end{array}$ & $\begin{array}{l}\text { Period } 1 \\
\mathrm{~N}=48\end{array}$ & $\begin{array}{l}\text { Period } 2 \\
\mathrm{~N}=42\end{array}$ \\
\hline MV in the first $72 \mathrm{~h}, \mathrm{n}(\%)$ & $72(79)$ & $41(57)^{*} \# \#$ & $28(65)$ & $11(37)^{*} \#$ & $44(92)$ & $30(71)^{*}$ \\
\hline $\begin{array}{l}\text { Duration of MV within the first } 72 \mathrm{~h}, \mathrm{~h} \text { (median) } \\
\text { [1st Qu; 3rd Qu] }\end{array}$ & $\begin{array}{l}13 \\
{[3-48]}\end{array}$ & $\begin{array}{l}7^{*} \# \\
{[0-30]}\end{array}$ & $\begin{array}{l}8 \\
{[0-17]}\end{array}$ & $\begin{array}{l}0 \\
{[0-13]}\end{array}$ & $\begin{array}{l}45 \\
{[9-72]}\end{array}$ & $\begin{array}{l}13^{* *} \\
{[0-43]}\end{array}$ \\
\hline $\begin{array}{l}\text { Duration of MV, d (median) } \\
\text { [1st Qu; 3rd Qu] }\end{array}$ & $\begin{array}{l}1 \\
{[0-6]}\end{array}$ & $\begin{array}{l}1 \\
{[0-6]}\end{array}$ & $\begin{array}{l}0 \\
{[0-1]}\end{array}$ & $\begin{array}{l}0 \\
{[0-1]}\end{array}$ & $\begin{array}{l}5 \\
{[1-24]}\end{array}$ & $\begin{array}{l}4 \\
{[0-10]}\end{array}$ \\
\hline $\begin{array}{l}\text { Duration of NIV, d (median) } \\
\text { [1st Qu; 3rd Qu] }\end{array}$ & $\begin{array}{l}27 \\
{[6-40]}\end{array}$ & $\begin{array}{l}27 \\
{[8-35]}\end{array}$ & $\begin{array}{l}13 \\
{[3-28]}\end{array}$ & $\begin{array}{l}13 \\
{[7-25]}\end{array}$ & $\begin{array}{l}37 \\
{[26-45]}\end{array}$ & $\begin{array}{l}32 \\
{[23-39]}\end{array}$ \\
\hline HFO, n (\%) & $26(29)$ & $34(48)^{*} \# \#$ & $2(5)$ & $6(21) \#$ & $24(50)$ & 28 (67)\# \\
\hline 2nd dose of Surfactant, n (\%) & $19(21)$ & $6(8)^{*} \# \#$ & $2(5)$ & $1(3)$ & $17(35)$ & $5(12)^{*} \# \#$ \\
\hline INSURE Procedure, n (\%) & $2(2)$ & $11(15)^{*} \# \#$ & $0(0)$ & $5(17)^{*}$ & $2(4)$ & $6(14)$ \\
\hline Postnatal Corticosteroids, n (\%) & $28(31)$ & $9(13)^{*} \# \#$ & $3(7)$ & $1(3)$ & $25(52)$ & $8(19)^{*} \# \#$ \\
\hline
\end{tabular}

VLGAI Very low gestational age infants < 32 weeks, ELGAl Extremely low gestational age infants < 29 weeks, MV Mechanical ventilation, NIV Noninvasive ventilation, HFO High frequency oscillation, INSURE Intubation-surfactant-extubation; *: $p<0.05$; **: $p<0.01$; \#: adjusted $p<0.05$; \#\#: adjusted $p<0.01$; *\#: $\mathrm{p}$ and adjusted $p<$ $0.05 ; * \#$ : $\mathrm{p}$ and adjusted $p<0.01$

rate was multiplied by 4 in the 29 - to 31 -week stratum. The rate of administration of a second dose of surfactant significantly decreased by $62 \%$ ( $\mathrm{p}$ and adjusted $p<0.01$ ) and 67\% (p and adjusted $p<0.01$ ) in VLGAI and ELGAI, respectively. The INSURE practice significantly increased from 2 to $15 \%$ in VLGAI ( $\mathrm{p}$ and adjusted $p<0.01$ ) and specifically in the 29- to 31-week subgroup from 0 to $17 \%(p<0.05)$ without reaching significance in the ELGAI subgroup $(p=0.14)$. In VLGAI and ELGAI, postnatal corticosteroid therapy decreased significantly by $58 \%$ ( $\mathrm{p}$ and adjusted $p<0.01$ ) and 63\% (p and adjusted $p<0.01)$, respectively.

\section{Neonatal morbidity and mortality (Table 4)}

BPD was significantly divided by 5 in VLGAI ( $\mathrm{p}$ and adjusted $<0.01$ ), disappeared in the 29- to 31-week stratum without reaching significance, and was significantly divided by 4 in the ELGAI subgroup ( $\mathrm{p}$ and adjusted $p<$ 0.05). No significant difference in overall mortality and early mortality within the first $72 \mathrm{~h}$ of life were shown between the two periods and subgroups. The combined $\mathrm{BPD} /$ mortality rate decrease of about $40 \%$ did not reach a statistically significant difference in VLGAI $(p=0.16)$ nor in the ELGAI subgroup $(p=0.21)$.

No statistically significant difference of neonatal morbidities during both periods and subgroups was observed.

\section{Discussion}

This retrospective cohort study compared the shortterm and before discharge neonatal morbidity and mortality of a new LR strategy combining individualized increase in PEEP and SI. This LR policy is retrospectively associated with a decrease in i) endotracheal intubation and surfactant administration in the DR, ii) rate

Table 4 Neonatal Mortality and Morbidity

\begin{tabular}{|c|c|c|c|c|c|c|}
\hline & \multicolumn{2}{|l|}{ VLGAI } & \multicolumn{2}{|c|}{ 29- to 31-wk stratum } & \multicolumn{2}{|l|}{ ELGAI } \\
\hline & $\begin{array}{l}\text { Period } 1 \\
\mathrm{~N}=91\end{array}$ & $\begin{array}{l}\text { Period } 2 \\
N=72\end{array}$ & $\begin{array}{l}\text { Period } 1 \\
N=43\end{array}$ & $\begin{array}{l}\text { Period } 2 \\
N=30\end{array}$ & $\begin{array}{l}\text { Period } 1 \\
N=48\end{array}$ & $\begin{array}{l}\text { Period } 2 \\
N=42\end{array}$ \\
\hline Physiologic BPD at 36 weeks GA, n (\%) & $15(16)$ & $2(3) * \#$ & $4(9)$ & $0(0)$ & $11(23)$ & $2(5) * \#$ \\
\hline Mortality, n (\%) & $10(11)$ & $9(13)$ & $1(2)$ & $1(3)$ & $9(19)$ & $8(19)$ \\
\hline Mortality within the first 72 h, n (\%) & $4(4)$ & $2(3)$ & $1(2)$ & $0(0)$ & $3(6)$ & $2(5)$ \\
\hline BPD and/or mortality, n (\%) & $25(27)$ & $11(15)$ & $5(12)$ & $1(3)$ & $20(42)$ & $10(24)$ \\
\hline Pneumothorax, n (\%) & $1(1)$ & $2(3)$ & $0(0)$ & $0(0)$ & $1(2)$ & $2(5)$ \\
\hline Treated PDA, n (\%) & $15(17)$ & $13(18)$ & $0(0)$ & $2(7)$ & $15(31)$ & $11(26)$ \\
\hline NEC $\geq$ grade $2 a, n(\%)$ & $4(4)$ & $4(6)$ & $1(2)$ & $1(3)$ & $3(6)$ & $3(7)$ \\
\hline IVH > grade $2, \mathrm{n}(\%)$ & $3(3)$ & $3(4)$ & $0(0)$ & $0(0)$ & $3(6)$ & $3(7)$ \\
\hline Periventricular leukomalacia, n (\%) & $4(4)$ & $0(0)$ & $2(4)$ & $0(0)$ & $2(4)$ & $0(0)$ \\
\hline ROP > grade 2, n (\%) & $1(1)$ & $0(0)$ & $0(0)$ & $0(0)$ & $1(2)$ & $0(0)$ \\
\hline
\end{tabular}

VLGAI Very low gestational age infants $<32$ weeks, BPD Bronchopulmonary dysplasia, PDA Patent ductus arteriosus, NEC Necrotizing enterocolitis, IVH Intraventricular hemorrhage, ROP Retinopathy of prematurity; *\#: $\mathrm{p}$ and adjusted $p<0.05 ;{ }^{*} \#$ : $\mathrm{p}$ and adjusted $p<0.01$ 
and duration of mechanical ventilation in the first $72 \mathrm{~h}$, iv) administration of a 2nd dose of surfactant, v) postnatal corticosteroids treatment and vi) BPD rate. Moreover, this strategy was not associated with any significant increase in neonatal morbidity or mortality.

The adherence to the new protocol was good but could have been better as $25 \%$ of the newborns did not benefitted from the LR maneuvers. Although their baseline characteristics did not differ from the 2016 population, they were excluded from the final analysis. For the remaining infants, the not significant but expected increased median maximal SI duration and PEEP level in the lower GA-based subgroup [17], confirms the understanding by the medical team of the individualized stepwise LR maneuvers. In a hindsight, to improve the adherence, more than 6 months should have been probably dedicated to educate the medical team and/or a video recording and reviewing program implemented.

Our significant decrease in endotracheal intubation rate in the DR is in accordance with other retrospective studies [18, 19] and 3 RCTs [20-22] on SI. However, in our study as in all retrospective studies in the DR, it is difficult to ascertain whether this decrease was related to our individualized LR maneuvers or to a longer time allowed to the infants to stabilize without intubation. Nevertheless, in favor of our LR maneuvers we observed a decrease of intubation rate in the DR with all physicians, not only the "early intubators". Nonetheless, only an RCT could add any definitive evidence on this subject. Laryngeal closure is described as the main cause of airway obstruction [23] impeding NIV in the DR in about 26\% of VLGAI [24]. In our 2016 cohort, apneic airway obstructions were also observed but only $18 \%$ of our VLGAIs were intubated for this reason in the DR, that is, on average in our medical team, twice a year per physician.

Surfactant administration in the DR decreased significantly, especially in ELGAI, showing the better transition to ex-utero life after LR maneuvers. Later, the paradoxical significant lower rate of a 2nd dose of surfactant despite the decreased $\mathrm{FiO}_{2}$ threshold and the increased lower $\mathrm{SpO}_{2}$ target range may illustrate the benefits of any recruiting maneuver: when a higher FRC is recruited before surfactant administration, more alveoli benefit from it, thus decreasing the eventual need for a 2 nd dose. The same explanation may apply to the INSURE procedure: a better recruitment increasing its chance of success.

Although the total MV duration did not reach a statistically significant decrease, pulmonary morbidity was reduced, as witnessed by a significantly lessened incidence of $\mathrm{MV}$ in the first $72 \mathrm{~h}$, duration of MV within the first $72 \mathrm{~h}$, surfactant and postnatal corticosteroids administrations. However, HFO ventilation because of its earlyrescue introduction, and the INSURE procedure were significantly more practiced during 2016. Although only the INSURE procedure is a long established beneficial practice [25], both changes might have contributed to some pulmonary protection.

A drastic fall in BPD rate was observed in both subgroups, without reaching significance in the 29- to 31-week subgroup despite its disappearance, probably because the relatively low prevalence of BDP in this subgroup makes a significant decrease more difficult to achieve.

Our data showed a steady state in mortality and early mortality within the first $72 \mathrm{~h}$ of life. This is unlike the large multicentric "Sustained Aeration of Infants Lungs" (SAIL) trial comparing SI with conventional ventilation in the DR which was recently cancelled (after 426 infants analyzed) because of a significant excess of deaths at less than $48 \mathrm{~h}$ of age in the intervention arm without any reduction in BPD rates in preterm infants $<27$ weeks GA [26]. Our speculative explanation of this harmful finding could be that the most immature infants may require an individualized and gentler support than a $15 \mathrm{~s}$ SI from the outset, explaining the initial persistent bradycardia observed in the SI group of the SAIL trial, and reflecting potential lung overdistention. In fact, our available data in preterm infants < 27 weeks GA show that only $27 \%$ required an $\mathrm{SI}=15 \mathrm{~s}$ with a $\mathrm{PEEP}=15 \mathrm{cmH} 2 \mathrm{O}$.

The combined BPD and/or mortality rate decreased by more than $40 \%$ but without reaching significance. The paradoxical absence of lowered mortality despite the better pulmonary outcomes may be related to an outbreak of first week late-onset septic shock during 2016 (i.e., 6 septic shock cases instead of 2 during the first period) while the overall rate of culture-proven sepsis remained steady ( 8 then 9 cases per year). We speculate that this increased mortality by septic shock might be related to some delay in sepsis management among medical and nurse teams unaccustomed to early NIV.

Our results are in accordance with all other retrospective studies $[18,19,27,28]$ assessing SI. Only one [18] showed a decrease in BPD and severe IVH, but these results could be related to other interventions in the DR such as an individualized approach to intubation, more CPAP use, and novel thermoregulation interventions. Four RCTs showed no benefits at all [20, 29-31]. However, according to the meta-analysis of Bruschettini et al. [10], a decreased duration of MV was found (mean difference: -5.37 days; $95 \%$ CI: -6.31 to -4.43 ), but without differences in the rate of BPD nor combined mortality/BPD. Whether our positive results could be explained only by the adjunction of the possibly more protective dynamic PEEP LR manoeuver [32] should be addressed in a specific RCT.

Two studies using a prophylactic approach with a fixed duration of SI [31,33] have shown a nonsignificant increase in the rate of pneumothorax from 1 to $6 \%$ 
(OR $=4.57 ; 95 \%$ CI: $0.97-21.5 ; p=0.06)$ [31] and from 0 to $3 \%(p=0.08)$ [33]. Only one more case was found in our study, despite the application of repeated SIs associated with much higher PEEPs. To explain this discrepancy, we postulate that our individualized approach might play a fundamental role. The rate of treated PDA was slightly but significantly increased in the metaanalysis of Schmölzer et al. $(\mathrm{RR}=1.27(1.05-1.54))$ [34], but our data do not support this observation.

A nonsignificant $27 \%$ increase in the rate of cesarean sections was observed during $2016(p=0.06)$. Paradoxically, our results show immediate benefits of the LR strategy, despite the absence of improved clearance of lung fluid that occurs during vaginal delivery [35]. Until recently, one of the described mechanisms of airway liquid clearance at birth was $\mathrm{Na}^{+}$uptake across the airway epithelium. However, this cellular mechanism develops only in late gestation [36], and is too slow to clear the volume of liquid to be expelled within seconds to minutes after birth from airways. Therefore, the airway liquid clearance after birth is thought to result from an increase in the transepithelial pressure gradient, occurring during inspiration, which is incompletely effective in premature neonates [7]. Thus, our results might validate that personalized LR maneuvers helped to clear the fluid-filled airways and initiate gas exchange.

This study shares the limitations of monocentric retrospective cohort studies. Thus, the steady high rate of IUGR observed in our population $(\sim 24 \%)$ could account for a greater rate of morbidities. Given the changes that occurred in our neonatal management, confounding factors were introduced such as lowering the $\mathrm{FiO} 2$ threshold for surfactant administration, INSURE procedure, volume guarantee ventilation, early-rescue HFO, permissive hypercapnia, individualized doubling of the caffeine maintenance dose, and individualized sedation-analgesia. All of these factors may have protected the developing lung, and heavily influenced the pulmonary outcomes. Moreover, the multiple secondary statistical analyses made in this study limit the value of significant results. Therefore, the beneficial pulmonary outcomes must be interpreted very cautiously except probably for the intubation and surfactant administration in the DR which could not be impacted by the subsequent management changes.

\section{Conclusions}

In conclusion, this retrospective study shows the feasibility of an individualized LR strategy based on a stepwise increase in PEEP and SI with potentially beneficial short-term neonatal outcomes. A large RCT is needed to confirm these results.

\section{Abbreviations}

BPD: Bronchopulmonary dysplasia; CPAP: Continuous positive airway pressure; CPR: Cardiopulmonary resuscitation; DR: Delivery room;
ELGAI: Extremely low gestational age infants; FiO2: Fraction of inspired oxygen; GA: Gestational age; HR: Heart rate; HFO: High frequency oscillation; INSURE: Intubation-surfactant-extubation; IUGR: Intrauterine restriction growth; IVH: Intraventricular hemorrhage; LR: Lung recruitment; MV: Mechanical ventilation; NEC: Necrotizing enterocolitis; NICU: Neonatal intensive care unit; NIV: Noninvasive ventilation; PDA: Patent ductus arteriosus; PEEP: Positive end-expiratory pressure; RCT: Randomized controlled trial; ROP: Retinopathy of prematurity; SI: Sustained inflation; SpO2: Pulse oxygen saturation; VLGAl: Very low gestational age infants

\section{Acknowledgments}

The authors gratefully acknowledge the members of the Delafontaine Hospital Neonatal Intensive Care Unit's medical team (by alphabetical order): Drs. F. Abouassi, M. Alchaar, C. Allioux, O. Girard, F. Harbi, F. ImestourenGoudjil, A. Saïd-Idrissi, and N. Semaan.

\section{Authors' contributions}

PW conceptualized and designed the study, supervised data collection and collected data, analyzed and interpreted data, reviewed and revised the manuscript. ZK collected data, carried out the initial statistical analysis, drafted the initial manuscript, reviewed and revised the manuscript. MB carried out statistical analyses, contributed to analysis and interpretation of data, reviewed and revised the manuscript. PB, CB-Q and VL contributed to analysis and interpretation of data, reviewed and revised the manuscript. The authors read and approved the final manuscript.

\section{Funding}

No external funding for this manuscript.

\section{Availability of data and materials}

The datasets used and analyzed during the current study are available from the corresponding author on reasonable request.

\section{Ethics approval}

Data collection was approved by the local area ethics committee on human research named Comité Local d'Ethique d'Avicenne (Hôpital Avicenne, Bobigny 93, France) and belonging to Groupe Hospitalier Paris-Seine-SaintDenis which allowed a waiver of informed consent for this retrospective study (Protocol No. CLEA-2017-031).

\section{Consent for publication}

Not applicable.

\section{Competing interests}

The authors declare that they have no competing interests.

\section{Author details}

${ }^{1}$ Service de Réanimation Néonatale et Néonatalogie, Hôpital Delafontaine, 2 rue Dr Delafontaine, 93205 Saint-Denis, France. ${ }^{2}$ Unité de Recherche Clinique, Groupe Hospitalier Paris Seine Saint-Denis, APHP, Bobigny, France.

Received: 17 October 2019 Accepted: 27 March 2020

Published online: 01 April 2020

\section{References}

1. Lista G, Maturana A, Moya FR. Achieving and maintaining lung volume in the preterm infant: from the first breath to the NICU. Eur J Pediatr. 2017; 176(10):1287-93. https://doi.org/10.1007/s00431-017-2984-y.

2. McCall KE, Davis PG, Owen LS, Tingay DG. Sustained lung inflation at birth: what do we know, and what do we need to know? Arch Dis Child Fetal Neonatal Ed. 2016;101(2):F175-80. https://doi.org/10.1136/archdischild-2015309611.

3. Tingay DG, Bhatia R, Schmolzer GM, Wallace MJ, Zahra VA, Davis PG. Effect of sustained inflation vs. stepwise PEEP strategy at birth on gas exchange and lung mechanics in preterm lambs. Pediatr Res. 2014;75(2):288-94. https://doi.org/10.1038/pr.2013.218.

4. Tingay DG, Rajapaksa A, McCall K, Zonneveld CE, Black D, Perkins E, et al. The interrelationship of recruitment maneuver at birth, antenatal steroids, and exogenous surfactant on compliance and oxygenation in preterm lambs. Pediatr Res. 2016;79(6):916-21. https://doi.org/10.1038/pr.2016.25. 
5. Tingay DG, Rajapaksa A, Zannin E, Pereira-Fantini PM, Dellaca RL, Perkins EJ, et al. Effectiveness of individualized lung recruitment strategies at birth: an experimental study in preterm lambs. Am J Physiol Lung Cell Mol Physiol. 2017;312(1):L32-41. https://doi.org/10.1152/ajplung.00416.2016.

6. Tingay DG, Rajapaksa A, Zonneveld CE, Black D, Perkins EJ, Adler A, et al. Spatiotemporal aeration and lung injury patterns are influenced by the first inflation strategy at birth. Am J Respir Cell Mol Biol. 2016;54(2):263-72. https://doi.org/10.1165/rcmb.2015-01270C.

7. Hooper SB, Te Pas AB, Kitchen MJ. Respiratory transition in the newborn: a three-phase process. Arch Dis Child Fetal Neonatal Ed. 2016;101(3):F266-71. https://doi.org/10.1136/archdischild-2013-305704

8. Wyckoff MH, Aziz K, Escobedo MB, Kapadia VS, Kattwinkel J, Perlman JM, et al. Part 13: neonatal resuscitation: 2015 American Heart Association guidelines update for cardiopulmonary resuscitation and emergency cardiovascular care. Circulation. 2015;132(18 Suppl 2):S543-60. https://doi. org/10.1161/CIR.0000000000000267.

9. Wyllie J, Bruinenberg J, Roehr CC, Rudiger M, Trevisanuto D, Urlesberger B. European resuscitation council guidelines for resuscitation 2015: section 7. Resuscitation and support of transition of babies at birth. Resuscitation. 2015;95:249-63. https://doi.org/10.1016/j.resuscitation.2015.07.029.

10. Bruschettini M, O'Donnell CP, Davis PG, Morley CJ, Moja L, Zappettini S, et al. Sustained versus standard inflations during neonatal resuscitation to prevent mortality and improve respiratory outcomes. Cochrane Database Syst Rev. 2017;7:CD004953. https://doi.org/10.1002/14651858.CD004953.pub3.

11. Fischer HS, Schmolzer GM, Cheung PY, Buhrer C. Sustained inflations and avoiding mechanical ventilation to prevent death or bronchopulmonary dysplasia: a meta-analysis. Eur Respiratory Rev. 2018;27(150). https://doi.org/ 10.1183/16000617.0083-2018.

12. Walsh MC, Yao Q, Gettner P, Hale E, Collins M, Hensman A, et al. Impact of a physiologic definition on bronchopulmonary dysplasia rates. Pediatrics. 2004;114(5):1305-11. https://doi.org/10.1542/peds.2004-0204.

13. Papile LA, Burstein J, Burstein R, Koffler H. Incidence and evolution of subependymal and intraventricular hemorrhage: a study of infants with birth weights less than 1,500 gm. J Pediatr. 1978;92(4):529-34.

14. Nwaesei CG, Pape KE, Martin DJ, Becker LE, Fitz CR. Periventricular infarction diagnosed by ultrasound: a postmortem correlation. J Pediatr. 1984;105(1): 106-10.

15. Walsh MC, Kliegman RM. Necrotizing enterocolitis: treatment based on staging criteria. Pediatr Clin North Am. 1986;33(1):179-201.

16. International Committee for the Classification of Retinopathy of P. The international classification of retinopathy of prematurity revisited. Arch Ophthalmol. 2005;123(7):991-9. https://doi.org/10.1001/archopht.123.7.991.

17. McCall KE, Waldmann AD, Pereira-Fantini P, Oakley R, Miedema M, Perkins $E J$, et al. Time to lung aeration during a sustained inflation at birth is influenced by gestation in lambs. Pediatr Res. 2017:82(4):712-20. https://doi. org/10.1038/pr.2017.141

18. Lindner W, Vossbeck S, Hummler H, Pohlandt F. Delivery room management of extremely low birth weight infants: spontaneous breathing or intubation? Pediatrics. 1999:103(5 Pt 1):961-7.

19. Grasso C, Sciacca P, Giacchi V, Carpinato C, Mattia C, Palano GM, et al. Effects of sustained lung inflation, a lung recruitment maneuver in primary acute respiratory distress syndrome, in respiratory and cerebral outcomes in preterm infants. Early Hum Dev. 2015;91(1):71-5. https://doi.org/10.1016/j. earlhumdev.2014.12.002

20. te Pas AB, Walther FJ. A randomized, controlled trial of delivery-room respiratory management in very preterm infants. Pediatrics. 2007;120(2):3229. https://doi.org/10.1542/peds.2007-0114.

21. El-Chimi MS, Awad HA, El-Gammasy TM, El-Farghali OG, Sallam MT, Shinkar DM. Sustained versus intermittent lung inflation for resuscitation of preterm infants: a randomized controlled trial. J Maternal-Fetal Neonatal Med. 2017; 30(11):1273-8. https://doi.org/10.1080/14767058.2016.1210598.

22. Jiravisitkul P, Rattanasiri S, Nuntnarumit P. Randomised controlled trial of sustained lung inflation for resuscitation of preterm infants in the delivery room. Resuscitation. 2017;111:68-73. https://doi.org/10.1016/j.resuscitation. 2016.12.003

23. Crawshaw JR, Kitchen MJ, Binder-Heschl C, Thio M, Wallace MJ, Kerr LT, et al. Laryngeal closure impedes non-invasive ventilation at birth. Arch Dis Child Fetal Neonatal Ed. 2018;103(2):F112-9. https://doi.org/10.1136/archdischild2017-312681.

24. Schmolzer GM, Dawson JA, Kamlin CO, O'Donnell CP, Morley CJ, Davis PG Airway obstruction and gas leak during mask ventilation of preterm infants in the delivery room. Arch Dis Child Fetal Neonatal Ed. 2011;96(4):F254-7. https://doi.org/10.1136/adc.2010.191171.

25. Stevens TP, Harrington EW, Blennow M, Soll RF. Early surfactant administration with brief ventilation vs. selective surfactant and continued mechanical ventilation for preterm infants with or at risk for respiratory distress syndrome. The Cochrane database of systematic reviews (4): CD003063. 2007. https://doi.org/10.1002/14651858.CD003063.pub3.

26. Kirpalani H, Ratcliffe SJ, Keszler M, Davis PG, Foglia EE, Te Pas A, et al. Effect of sustained inflations vs intermittent positive pressure ventilation on bronchopulmonary dysplasia or death among extremely preterm infants: the SAIL randomized clinical trial. Jama. 2019;321(12):1165-75. https://doi. org/10.1001/jama.2019.1660.

27. Lista G, Fontana P, Castoldi F, Cavigioli F, Dani C. Does sustained lung inflation at birth improve outcome of preterm infants at risk for respiratory distress syndrome? Neonatology. 2011;99(1):45-50. https://doi.org/10.1159/ 000298312.

28. Buyuktiryaki M, Kanmaz HG, Okur N, Bezirganoglu H, Ozer Bekmez B, Simsek GK, et al. Sustained lung inflation at birth via short binasal prong in very low birth weight preterm infants: a retrospective study. Pediatr Pulmonol. 2018;53(10):1407-13. https://doi.org/10.1002/ppul.24130.

29. Lindner W, Hogel J, Pohlandt F. Sustained pressure-controlled inflation or intermittent mandatory ventilation in preterm infants in the delivery room? A randomized, controlled trial on initial respiratory support via nasopharyngeal tube. Acta Paediatr. 2005;94(3):303-9.

30. Harling AE, Beresford MW, Vince GS, Bates M, Yoxall CW. Does sustained lung inflation at resuscitation reduce lung injury in the preterm infant? Arch Dis Child Fetal Neonatal Ed. 2005;90(5):F406-10. https://doi.org/10.1136/adc. 2004.059303.

31. Lista G, Boni L, Scopesi F, Mosca F, Trevisanuto D, Messner H, et al. Sustained lung inflation at birth for preterm infants: a randomized clinical trial. Pediatrics. 2015;135(2):e457-64. https://doi.org/10.1542/peds.2014-1692.

32. Tingay DG, Pereira-Fantini PM, Oakley R, McCall KE, Perkins EJ, Miedema M, et al. Gradual aeration at birth is more lung protective than a sustained inflation in preterm lambs. Am J Respir Crit Care Med. 2019. https://doi.org/ 10.1164/rccm.201807-13970C.

33. Mercadante D, Colnaghi M, Polimeni V, Ghezzi E, Fumagalli M, Consonni D, et al. Sustained lung inflation in late preterm infants: a randomized controlled trial. J Perinatol: official journal of the California Perinatal Association. 2016;36(6):443-7. https://doi.org/10.1038/jp.2015.222.

34. Schmolzer GM, Kumar M, Aziz K, Pichler G, O'Reilly M, Lista G, et al. Sustained inflation versus positive pressure ventilation at birth: a systematic review and meta-analysis. Arch Dis Child Fetal Neonatal Ed. 2015;100(4): F361-8. https://doi.org/10.1136/archdischild-2014-306836.

35. Jain L, Dudell GG. Respiratory transition in infants delivered by cesarean section. Semin Perinatol. 2006;30(5):296-304. https://doi.org/10.1053/j. semperi.2006.07.011.

36. Hummler E, Planes C. Importance of ENaC-mediated sodium transport in alveolar fluid clearance using genetically-engineered mice. Cell Physiol Biochem. 2010;25(1):63-70. https://doi.org/10.1159/000272051.

\section{Publisher's Note}

Springer Nature remains neutral with regard to jurisdictional claims in published maps and institutional affiliations.

Ready to submit your research? Choose BMC and benefit from:

- fast, convenient online submission

- thorough peer review by experienced researchers in your field

- rapid publication on acceptance

- support for research data, including large and complex data types

- gold Open Access which fosters wider collaboration and increased citations

- maximum visibility for your research: over $100 \mathrm{M}$ website views per year

At $\mathrm{BMC}$, research is always in progress.

Learn more biomedcentral.com/submission 